\title{
Option Derivatives in Electricity Hedging
}

\author{
P. Pavlatka
}

\begin{abstract}
Despite the high volatility of electricity prices, there is still little demand for electricity power options, and the liquidity on the power exchanges of these power derivatives is quite low. One of the reasons is the uncertainty about how to evaluate these electricity options and about finding the right fair value of this product. Hedging of electricity is associated mainly with products such as futures and forwards. However, due to new trends in electricity trading and hedging, it is also useful to think more about options and the principles for working with them in hedging various portfolio positions and counterparties. We can quite often encounter a situation when we need to have a perfect hedge for our customer's (end user consuming electricity) portfolio, or we have to evaluate the volumetric risk (inability of a customer to predict consumption, which is very similar to selling options. Now comes the moment to compare the effects of using options or futures to hedge these open positions. From a practical viewpoint, the Black-Scholes prices appear to be the best available and the simplest method for evaluating option premiums, but there are some limitations that we have to consider.
\end{abstract}

Keywords: option derivatives, electricity hedging, evaluation models, electricity prices.

\section{Key features of electricity prices}

Some years ago, the electricity market was vertically integrated and the prices of this commodity were fully regulated by state-owned authority managed worldwide. These regulated prices had to reflect the cost of electricity generation, transmission and distribution. The prices were therefore determined by well-known factors, and changed only rarely. Since deregulation of the electricity market, prices have been determined according to the economic rule of supply and demand. Many countries have settled electricity pools, where bids of electricity sellers are matched with the purchase orders of end users. These pools trade with long-term products and also with short-term products. The differences are only in liquidity and volatility. This deregulation has fully supported trading activities on the derivatives markets, which allow trading with financial electricity contracts as derivatives, where electricity is the underlying asset. The relatively high volatility of electric power and important specifics of this commodity have forced many market players to manage price risk professionally. Hedging market risks is a well-known way to eliminate the risk of price changes, but there are also weak points, which are associated with specific features of electricity. Due to the obvious specific features of electricity, e.g. its unique nonstorability, electricity prices are more likely to be driven by spot supply and demand, which is inelastic. Any shock in consumption or production may give rise to price jumps [4].

\section{$2 \quad$ Hedging}

As the electricity market becomes deregulated and more competitive, changes in supply and demand are increasingly translated into price volatility and fluctuations. Another very important driver has been financial crises, which have shown us the impact of financial derivatives traded also on behalf of electricity contracts. Most of the volatility of the fluctuations in supply and demand is visible on the daily spot market, where the price is mainly influenced by inelastic demand and short-term supply. Figure 1 shows the increasing volatility of spot prices in recent years.

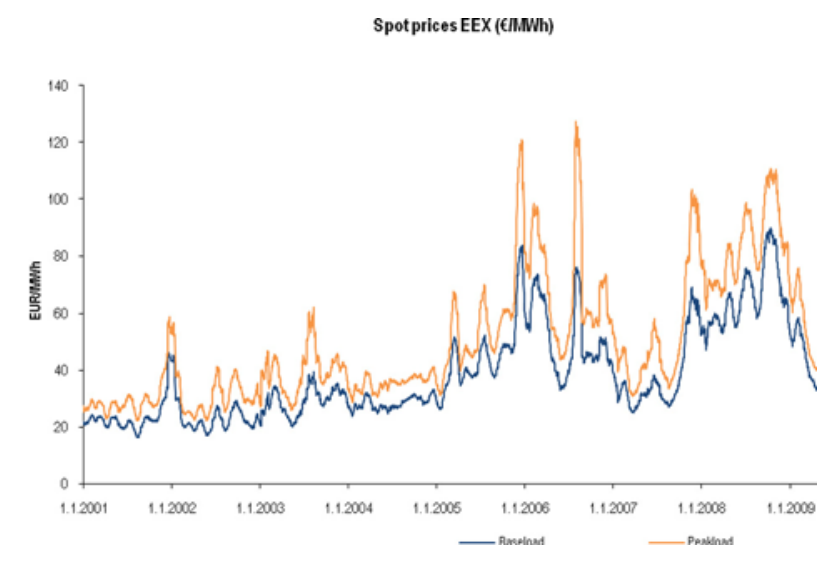

Fig. 1: Spot prices of electricity in $€ / M W h$ (source http://www.eex.com)

Most derivatives, however, are not typically used to hedge risks connected with daily price volatility. They 
are used to hedge risks associated with trend fluctuations and seasonal price volatility. Market participants therefore often use annual and monthly derivatives. In a competitive electricity market, daily fluctuations in electricity prices will therefore be the most dramatic driver of price volatility. There are two different approaches depending on the type of market participant. Generators, as entities owning power plants, have a natural "long" electricity position, and the value of this position increases and decreases with the price of power. When power prices increase, the value of the electricity produced increases, and when power prices decrease, the value of the produced commodity decreases. An electricity consumer is naturally "short" and, in the opposite way, consumers benefit when prices go down and have to suffer loss when prices increase. Price volatility introduces new risks for generators, consumers and traders (brokers). In a competitive electricity market, generators will have to sell some of the electric power that they produce in volatile spot markets, and will bear the risk if the spot prices are lower than the generation costs. In the case of consumers, we have to consider higher seasonal and hourly price variability. It is obvious that this uncertainty could make it more difficult to assess and manage a customers's long-term financial position. Electricity futures and other power derivatives help electricity generators and end consumer to hedge price risks (market risk) in a competitive electricity market. Futures contracts are legally binding and negotiable contracts that call for future delivery of electricity. In many cases, physical delivery does not take place, and the futures contract is closed by buying or selling a futures contract on the delivery date. Other power derivatives include options, price swaps, and OTC forward contracts. Power derivatives, like futures and options, are traded on an exchange where participants are required to deposit margins to cover all potential losses due to the credit risk of the counterparty and the market risk of an open position. Other hedging instruments, such as forwards, are traded bilaterally "over-the-counter". Recently we have seen how expensive membership of a power exchange is, and we can compare the costs of financial capital for margins with paid option premiums.

\subsection{Short-term or long-term hedging}

It is relative difficult to define a strict boundary between long-term hedging and short-term hedging. We could define short-term hedging in terms of the most distant maturity traded month contract on the power exchange. This could be between 6 and 12 months. The main important risks associated with short-term hedging are cash-flow problems. In the first case, a cash-flow problem emerges from an insufficient initial and variation margin for MtM ("Mark-to-Market").
The result is that the intended hedging transaction becomes to speculative position after a margin call that we are not able to pay for. In the second case, we can consider an unhedged price risk, which results from inadequate hedging of open positions. This case very often occurs and is associated with volumetric risk. Most electricity consumption depends on short-term conditions, and there are not enough strict plans or "take or pay" contracts, which will motivate the end customer to consume in order with the contracted volume. Gains and losses from hedging activities that occur in the futures market when a hedge is undertaken must be viewed as part of the electricity price that the market participant provides to its customers. The same approach has to be undertaken in the case of option premiums.

Sometimes a market player takes a profit in the futures market and loses in the spot market, and sometimes the reverse situation occurs. It is clear that hedging profits and losses must be treated simply as part of the cost of purchasing energy. With an imperfect hedge, the market player could earn less on his futures position than he loses between his fixed price contract and the spot market, or he could earn more. There is no clear line to distinguish long-term and short-term hedging. The cash flow risk increases exponentially due to margin calls as the maturity of the long-term hedge increases. We consider that the increase in risk is faster than linear, for two reasons. Firstly, the price volatility increases approximately in proportion to the square root of the length of the hedge, and secondly, the amount being hedged is generally proportional to the length of the hedge, because the market player will be hedging an constant volume over the time. The primary risk associated with longterm hedging is again associated with margin calls risk. Now we can compare forward and futures contracts. A key difference between forward and futures contracts is in cash settlement, which is performed by a clearing bank in the case of futures. A buyer or seller of a futures contract will have to realize short term losses or gains as the futures price changes. This cash settlement is performed daily. In the case of a forward contract, profit and loss is realized only at maturity and there is no cash flow problem due to the payment of a variation margin. There is another more important specific consideration which could make forward dealing less interesting for smaller business units, and that is the credit risk exposure of an electricity seller. In the case of futures, this credit risk and also the market risk is solved by MtM (daily cash settlement) clearing. It is obvious that the money lost on the future is entirely regained from the added profit on the fixed price contract that was sold at the start of this example. If the loss is quite large, it may be impossible for the hedging market participants to raise the cash margins necessary to meet the variation margin requirement. 
In this case, the clearing bank has the right to liquidate all open positions of the counterparties. Hedging over longer periods puts traders at risk for extremely large margin calls. The consequence is that long-term hedging requires significant financial resources to meet variation margin requirements.

\subsection{Options}

In 1996, NYMEX introduced options for electricity. There are two types of options for electricity: a put option ("floor") and a call option ("cap"). In the first case, the buyer of an electricity put option pays a premium for the right, but not the obligation, to sell electricity at a specified price, the strike price or exercise price, at a specified exercise time. End users use call options to place a maximum cap price that they will pay for the commodity at a specified exercise time. Market participants often use combinations of calls and puts to ensure a particular price range. Generators often use put options to guarantee a minimum price of the produced electricity in conjunction with the physical sale of electricity. By this product, a generator could benefit from increases in commodity prices, but would avoid the risk of lower prices. Consider that the futures contract price is $€ 43 / \mathrm{MWh}$ and the generator of electricity would like to receive at least this amount due to profit analysis. Therefore, the generator has to purchase a put option, for $€ 2 / \mathrm{MWh}$, which the generator will pay for. If the price of electricity increases, the generator will sell electricity into the spot market and receive the higher spot price (see Figure). If the price of electricity falls, the generator will sell electricity to the option holder for $€ 43 / \mathrm{MWh}$, or he will sell his option at its exercise value, $€ 43 / \mathrm{MWh}$, on or before its expiration date.

Producer exercise (long put + long electricity)

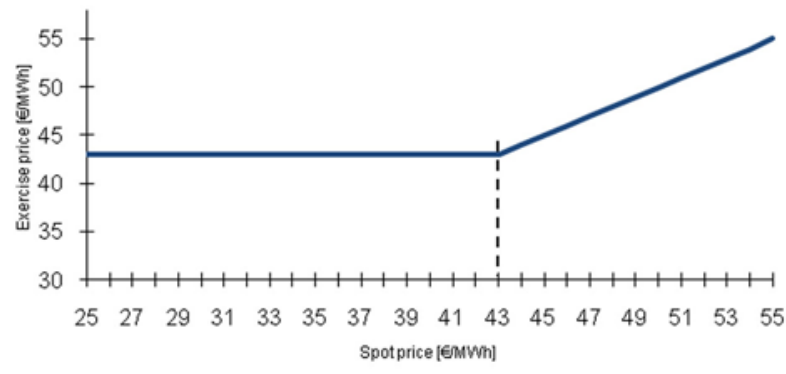

Fig. 2: Put option of an electricity producer

A consumer, end user, deals with the opposite problem. In the case of hedging, he would utilize a call option to avoid the risk of higher prices, while retaining the ability to participate in potentially lower prices. Let us assume that the futures contract price is $€ 40 / \mathrm{MWh}$ and the consumer would like to pay no more than this price. In this case, the customer will buy a call option; say for $€ 2 / \mathrm{MWh}$, which the end users have to pay in advice. If the price of electricity falls, the consumer will buy electricity in the spot market. If the price goes up, the end user will buy electricity from the option holder for $€ 40 / \mathrm{MWh}$ or will sell his call option for its exercise value, $€ 40 / \mathrm{MWh}$, on or before its expiration date.

\section{Option evaluation}

Market models for evaluating derivatives and options work mainly with storable commodities. The nonstorability of electricity implies a breakdown of the relationship between the spot price and the forward price (Eydeland and Geman 1988). The second problem is with convenience yield, which is important in many cases of commodities. The convenience yield is a numeric adjustment to the cost of carry in the nonarbitrage pricing formula for forward prices in markets. In the case of the money market we can consider the following situation. Let $F_{t, T}$ be the forward price of an asset with initial price $S_{t}$ and maturity $T$. We suppose that $r$ is the continuously compounded interest risk free rate. Then, the non-arbitrage pricing formula of the forward price is:

$$
F_{t, T}=S_{t} \mathrm{e}^{r(T-t)}
$$

However, this relationship does not exist in most commodity markets, partly because of the inability of investors and speculators to short the underlying asset. Instead, there is a correction to the forward pricing formula given by the convenience yield $c$. Hence

$$
F_{t, T}=S_{t} \mathrm{e}^{(r-c)(T-t)}
$$

The convenience yield exists because owners of the asset may obtain a benefit from physically holding this asset as inventory to maturity. These benefits include the ability to profit from temporary shortages. Anyone who owns inventory has the choice between consumption today versus investment for the future. A rational investor will choose the outcome that is best. When inventories are high, this suggests anticipated relatively low scarcity of the commodity today versus sometime in the future. Otherwise, the investor would sell his stocks and the forward prices $F_{t, T}$ of the asset should be higher than the current spot price $S_{t}$. This tells us that $r-c>0$. The reasoning become interesting in the case of low inventories, when we expect that the scarcity now is greater than it will be in the future. Therefore, the investor wants to borrow inventory from the future but is unable. We expect future prices to be lower than today and hence $F_{t, T}<S_{t}$. This implies that $r-c<0$.

The concept of convenience yield was introduced by Kaldor(1939) and Working(1949) for agricultural commodities. This concept represented the benefit from holding the commodity as opposed to a forward contract. The concept of convenience yield does not 
make sense in the case of electricity, because there is no available method to store electric power, and therefore we cannot consider the benefit from storing the commodity versus storing costs. The first, very important, characteristic of electricity prices is a mean reversion toward a level representing the marginal cost of electricity production, which can be constant, periodic or periodic with some trend. In the case of electricity we have to expect the mean to revert to a deterministic periodical trend driven by seasonal effects. The second specific driver of electricity prices is the existence of temporary imbalances of supply and demand in the network which affects random price moves around the average trend. We are not able to predict this effect. A third feature is the jump character of electricity prices (spikes), because shocks in power supply and demand cannot be smoothed away by inventories.

As was mentioned above, the convenience yield attached to a commodity can be interpreted as a continuous dividend payment made to the owner of the commodity. Then we could suppose that the price of the underlying asset is driven by a geometric Brownian motion and use Merton's (1973) formula for pricing options (3). This formula provides the price of a plain vanilla call option written on a commodity with price $S$ :

$$
C(t)=S(t) \mathrm{e}^{-y(T-t)} N\left(d_{1}\right)-k \mathrm{e}^{-r(T-t)} N\left(d_{2}\right),
$$

where

$$
\begin{aligned}
& d_{1}=\frac{\ln \left(\frac{S(t) \mathrm{e}^{-Y(T-t)}}{k \mathrm{e}^{-r(T-t)}}\right)+\frac{1}{2} \sigma^{2}(T-t)}{\sigma \sqrt{T-t}} \\
& d_{2}=d_{1}-\sigma \sqrt{T-t}
\end{aligned}
$$

As was mentioned above, the main difficulties in valuing power options are due to the fact that this commodity cannot be stored and the associated problem with convenience yield. The results of using formula (3) are very similar to the prices at the EEX pool. All inputs and results are obvious from Tab. 1.

\section{EEX Option CAL11}

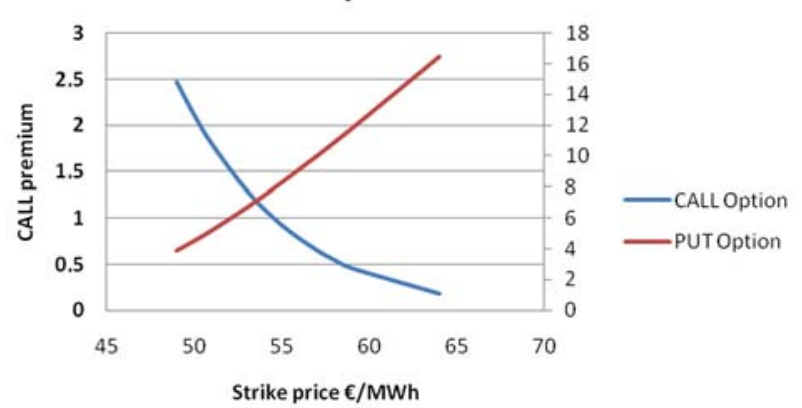

Fig. 3: Market data of a traded option (call/put, source http://www.eex.com)

\begin{tabular}{|c|c|c|}
\hline \multicolumn{3}{|c|}{ Market Data (EEX pricing) } \\
\hline contract & CAL2011 & \\
\hline \multirow[t]{2}{*}{ futures $€ / M W h$} & 47.58 & $€ / \mathrm{MWh}$ \\
\hline & \multicolumn{2}{|c|}{ premium $€ / M W h$} \\
\hline $\begin{array}{l}\text { Strike price } \\
\quad € / \mathrm{Mwh}\end{array}$ & CALL Option & PUT Option \\
\hline 49 & 2.47 & 3.88 \\
\hline 50 & 2.11 & 4.51 \\
\hline 51 & 1.80 & 5.19 \\
\hline 53 & 1.30 & 6.67 \\
\hline 55 & 0.92 & 8.28 \\
\hline 57 & 0.65 & 9.99 \\
\hline 58 & 0.55 & 10.87 \\
\hline 59 & 0.46 & 11.77 \\
\hline 64 & 0.18 & 16.45 \\
\hline \multicolumn{3}{|c|}{$\begin{array}{l}\text { Results of Black - Scholes formula }(3), \\
\text { volatility approx. } 16 \%\end{array}$} \\
\hline $\begin{array}{c}\text { Strike price } \\
€ / \mathrm{Mwh}\end{array}$ & CALL Option & PUT Option \\
\hline 49 & 2.12 & 3.51 \\
\hline 50 & 1.76 & 4.13 \\
\hline 51 & 1.45 & 4.80 \\
\hline 53 & 0.96 & 6.28 \\
\hline 55 & 0.62 & 7.90 \\
\hline 57 & 0.39 & 9.63 \\
\hline 58 & 0.30 & 10.53 \\
\hline 59 & 0.24 & 11.44 \\
\hline 64 & 0.06 & 16.17 \\
\hline
\end{tabular}

Table 1: Inputs and results of a comparison of EEX market data and an evaluation of formula (3)

\section{B-S premium vs. EEX market data}

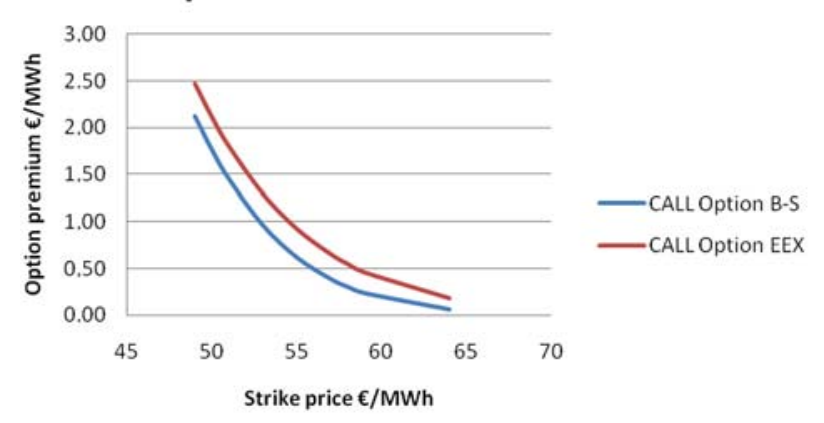

Fig. 4: Comparison of market data(EEX) with result of the B-S formula (3) 
The primary category of traded electricity options includes calendar year contracts and monthly physical options, which are also traded at pool EEX. Call options allow the buyer to receive power at the strike price. These options are relatively liquid. See the next figure with pricing of a set of options divided by the strike price. The results of using the B-S formula (3) are relevant in this case and after a comparison (see Fig. 4) with market pricings of options, they are very similar.

The second categories of options are daily options, or options for a block of hours. These (Asian type) options are specified for a given period of time and can be exercised every day during this period. It is obvious that daily options are very difficult to manage and are not liquid. Therefore it is important to work better with pricing models associated with jump characteristics and mean reverting of electricity prices.

\section{Conclusion}

Liberalization of the energy industry requires adaptation to risk-management techniques. Pricing or selling derivative products poses new challenges for market participants. The non-storability of electrical power and the inability to hold short positions in electricity spot prices has eliminated the utilization of techniques from financial mathematics. In the case of European type of derivatives in energy markets, namely options (call, put and collar), it turns out that these derivative prices are related to the standard Black-Scholes option pricing formula. The main important parameter for calculating fair value is volatility. These findings are positive, since the standard tool for pricing option derivatives can also be applied in power markets without losing the influence of specific market features.

\section{Acknowledgement}

The research described in this paper was supervised by Prof. O. Starý, FEE CTU in Prague

\section{References}

[1] Borovkova, S., Geman, H.: Analysis and Modeling of Electricity Futures Prices, Studies in Nonlinear Dynamics \& Econometrics, Nonlinear Analysis of Electricity Prices, Vol. 10, Issue 3, Article 6, The Berkeley Electronic Press, 2006.

[2] Hull, J. C.: Options, futures, and other derivatives. 6th edition, Prentice Hall, 2006, ISBN 0-13-149908-4.

[3] Redl, C.: Modeling Electricity Futures, Energy Economics Group, Vienna University.

[4] Stoft, S., Belden, T., Goldman, C., Pickle, S.: Primer on Electricity Futures and Other Derivatives, University of California, 1998.

\author{
About the author \\ Pavel PAVLATKA was born in Ceske Budejovice \\ in 1982. He was awarded a master's degree in Febru- \\ ary 2008. He is currently a doctoral student at the \\ Department of Economics, Management and Human- \\ ities, FEE, CTU in Prague. \\ Pavel Pavlatka \\ E-mail: Pavlap1@.fel.cvut.cz \\ Dept. of Economics \\ Management and Humanities \\ Czech Technical University \\ Zikova 4, 16629 Praha 6, Czech Republic
}

